\title{
Comparatively Evaluation of Surgical and Non-Surgical Treatment of Blunt Hepatic Trauma
}

\author{
Mohd Khalid ${ }^{*}$, Mohd Mubashir ${ }^{2}$ \\ ${ }^{1 *}$ Assistant Professor, ${ }^{2}$ Associate Professor, Department of Surgery, \\ Mayo Institute of Medical Sciences, Gadia, Dharsania, Barabanki, Uttar Pradesh, India.
}

\begin{abstract}
Background: Hepatic trauma comprises of $5 \%$ of all the emergency admissions in various hospitals. Ever since the advancement in the field of diagnosis has occurred, there has been an increase in the incidence of the cases of hepatic trauma. These diagnostic advancements have changes the treatment scenario of certain eligible patients from surgical to non-surgical management. Hence; we analyzed the outcome of surgical and non-surgical line of treatment in the management of blunt hepatic trauma cases in hemodynamic stable patients.

Materials \& Methods: The present study was conducted in the department of hepatic-surgery of the medical institution and included all the patients that reported in the institution with the history of hepatic trauma. All these 120 patients were included in the present study groups. All the patients were divided into two study groups. One group comprised of patients who were treated with non-surgical management while the other group comprised of individuals treated by surgical means of treatment. Complete assessment of the patients was done to exclude the requirement of surgical treatment by assessing the Glasgow coma scale and the extent of hepatic injury. If the patients didn't responded to the non-surgical treatment, requirement of the surgical treatment was confirmed and laparotomy was indicated. Demographic details and clinichaematological parameters were assessed at regular intervals. Post-operative complications were assessed and recorded. All the results were analyzed by SPSS software.
\end{abstract}

Results: Mean age of the patients undergoing surgical and non-surgical mode of treatment was 33.52 and 32.12 years respectively. 82.2 and 71.2 percent of the patients in surgical

\section{INTRODUCTION}

In abdominal trauma cases, one of the most common organ to injured because of it location is liver. Hepatic trauma comprises of $5 \%$ of all the emergency admissions in various hospitals. ${ }^{1}$ Ever since the advancement in the field of diagnosis has occurred, there has been an increase in the incidence of the cases of hepatic trauma. These diagnostic advancements have changes the treatment scenario of certain eligible patients from surgical to non-surgical management. ${ }^{2}$ It has been shown in the past literature study that in hemodynamically stable patients with blunt hepatic injuries, non-surgical treatment is more stable and safer in comparison with surgical management of these patients. ${ }^{3,4}$ and non-surgical groups were males. Mean Glasgow coma scale score in patients in two study groups was 11.01 and 15.02 respectively. $75.2 \%$ patients in surgical treated group and $78.2 \%$ patients in non-surgical treated groups were having grade I to IV head injury. 82.2 and 35.1 percent of the patients in surgical and non-surgical treated groups required blood transfusion. Liver related complications were seen in $41 \%$ and $4 \%$ of the individuals in the two study groups respectively. Significant difference was obtained while comparing the clinical parameters in between the two study groups.

Conclusion: Higher success rate of non-surgical treatment exists in patients having blunt hepatic trauma with hemodynamic stability.

Key Words: Hemodynamic, Hepatic, Trauma.

\section{*Correspondence to:}

Dr. Mohd Khalid

Assistant Professor, Department of Surgery,

Mayo Institute of Medical Sciences,

Gadia, Dharsania, Barabanki, Uttar Pradesh, India.

\section{Article History:}

Received: 21-08-2016, Revised: 06-09-2016, Accepted: 10-09-2016

\begin{tabular}{|l|r|}
\hline \multicolumn{2}{|c|}{ Access this article online } \\
\hline Website: & Quick Response code \\
www.ijmrp.com & \\
\hline DOl: & \\
10.21276/ijmrp.2016.2.5.031 &
\end{tabular}

Hence; we analyzed the outcome of surgical and non-surgical line of treatment in the management of blunt hepatic trauma cases in hemodynamic stable patients.

\section{MATEIRALS \& METHODS}

The present study was conducted in the department of hepaticsurgery of the medical institution and included all the patients that reported in the institution with the history of hepatic trauma from 2013 to 2015 . Over 240 patients reported to the emergency of the hospital out of which 120 patients reported with the chief complaint of blunt hepatic injury. Paediatric patients and patients 
who were referred to other hospitals were excluded from the present study. All these 120 patients were included in the present study groups. All the patients were divided into two study groups. One group comprised of patients who were treated with nonsurgical management while the other group comprised of individuals treated by surgical means of treatment. Non-surgical treatment consisted of treating patients initially by achieving stability of hemodynamic system followed by a thorough initial examination. Complete assessment of the patients was done to exclude the requirement of surgical treatment by assessing the Glasgow coma scale and the extent of hepatic injury. If the patients didn't responded to the non-surgical treatment, requirement of the surgical treatment was confirmed and laparotomy was indicated. Demographic details and clinico- haematological parameters were assessed at regular intervals. This involved assessment of systolic blood pressure (SBP) on admission, Glasgow Coma Scale (GCS), Revised Trauma Score (RTS), Injury Severity Score (ISS), probability of survival (TRISS), AIS head, ATI, grade of injury according to the Organ Injury Scale of the American Association for the Surgery of Trauma (OISAAST), presence of associated abdominal injuries, need for blood transfusion, amount of packed red blood cells, platelets and fresh frozen plasma transfusions, complications (related and nonrelated to the liver), need for surgical intervention, length of hospital stay and mortality. ${ }^{5-7}$ Post-operative complications were assessed and recorded. All the results were analyzed by SPSS software. The chi-square test and student $t$ test was used for the assessment of level of significance.

Table 1: $p$-value for various demographic and clinical details of the patients in two study groups.

\begin{tabular}{lccc}
\hline Parameter & Surgical treated cases & $\begin{array}{c}\text { Non-surgical treated } \\
\text { cases }\end{array}$ & p-value \\
\hline Mean age (years) & 33.52 & 32.12 & 0.120 \\
Males (\%) & 82.2 & 71.2 & 0.310 \\
Mean SBP on admission & 95.42 & 120.22 & $0.001^{*}$ \\
Mean Glasgow coma scale & 11.01 & 15.02 & $0.001^{*}$ \\
Grade I-IV head injury (\%) & 75.2 & 78.2 & 0.575 \\
Grade V head injury (\%) & 24.8 & 21.8 & 0.412 \\
Blood transfusion (\%) & 82.2 & 35.1 & $0.001^{*}$ \\
Mean packed red blood cell infused & 9.73 & 3.01 & $0.001^{*}$ \\
Complications related to liver (\%) & 41 & 4 & $0.001^{*}$ \\
Mortality (\%) & 42.5 & 2.1 & $0.001^{*}$ \\
Complications not related to liver (\%) & 60.5 & 11.2 & $0.001^{*}$ \\
\hline
\end{tabular}

Graph 1: Demographic and clinical details of the patients in two study groups.

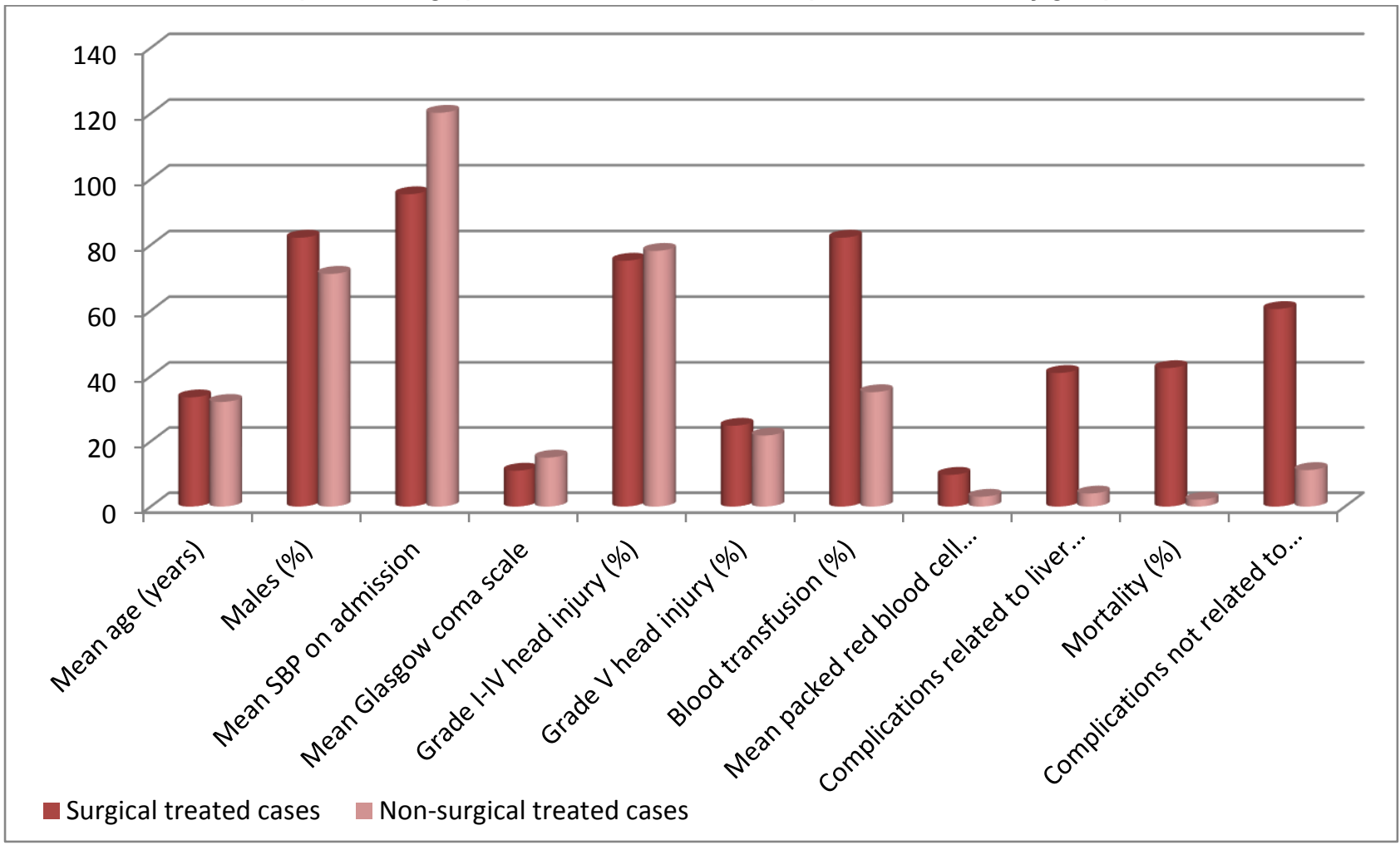




\section{RESULTS}

Graph 1 shows the demographic details of the patients in the two study groups. Mean age of the patients undergoing surgical and non-surgical mode of treatment was 33.52 and 32.12 years respectively. 82.2 and 71.2 percent of the patients in surgical and non-surgical groups were males. Mean Glasgow coma scale score in patients in two study groups was 11.01 and 15.02 respectively. 75.2 Percent patients in surgical treated group and 78.2 percent patients in non-surgical treated groups were having grade I to IV head injury. 82.2 and 35.1 percent of the patients in surgical and non-surgical treated groups required blood transfusion. Liver related complications were seen in $41 \%$ and 4 $\%$ of the individuals in the two study groups respectively. Table 1 shows the $p$-value for the statistical comparison of various clinical and demographic parameters of the two study groups. Significant difference was obtained while comparing the clinical parameters in between the two study groups.

\section{DISCUSSION}

The liver is the most frequently injured abdominal organ. Most hepatic injuries are relatively minor and heal spontaneously with nonoperative management which consists of observation, and possibly arteriography and embolization. ${ }^{8}$ In patients with penetrating liver injury, the severity of injury depends upon the trajectory of the missile or implement and injuries can range from simple parenchymal to major vascular laceration. ${ }^{9}$ Operative intervention to manage the liver injury is needed in about 14 percent of patients including those who initially present with hemodynamic instability or those who fail non-operative management. ${ }^{10}$ Hence; we analyzed the outcome of surgical and non-surgical line of treatment in the management of blunt hepatic trauma cases in hemodynamic stable patients.

In the present study, we observed that the hemodynamic status of the patients influences the decision of carrying out non-surgical treatment in the patients having blunt hepatic trauma injuries. Various hemodynamic parameters showed significant difference when compared in between the two study groups. We also observed that grade of hepatic injury have no effect on the outcome of the treatment. Essentially the hemodynamic status and various clinical parameters decide the prognosis of the surgical and non-surgical mode of treatment. Bismar et al evaluated the treatment of blunt liver trauma cases at Riyadh Central Hospital. They retrospectively analyzed the data records of the 68 patients admitted in the Riyadh medical hospital over a period of 5 years with the chief problem of blunt hepatic trauma. They divided their patients' data into two study groups. One group comprised of those patients that were hemodynamically stable and underwent non-surgical line of treatment while the other group included all those patients in which laparotomy was indicated and underwent surgical mode of treatment. Assessment of the followup records and tests was done to assess the presence or absence of complications. They observed that in the 5 years observation perios, 68 patients were treated. Out of which, 49 percent of the cases were treated with immediate surgical procedures. From the results, they concluded that in terms of safety and effectiveness in hemodynamically stable patients with blunt liver trauma, the nonsurgical mode of treatment is an equally successful mode of treatment. ${ }^{11}$ Ghnnam et al evaluated the data available on the management of blunt liver trauma cases in a trauma hospital in
Saudi Arabia. They prospectively evaluated 56 patients treated for blunt liver trauma over a 4-year period and divided their patients into two study groups. First group included patients who were hemodynamically stable and underwent non-surgical mode of treatment while the other group included patients that required conservative treatment in the intensive or intermediate care unit. Computed tomography of the abdomen was done before and after the treatment to assess the prognosis of the treatment. Follow-up records of the patients were maintained and assessed. They observed that out of total 56 patients treated in their study, 20 out them were treated with immediate surgical mode of treatment. 36 patients underwent non-surgical mode of treatment. From the results, they concluded that in terms of effectiveness of hemodynamically stable patients, non-surgical mode of treatment is equally successful in comparison with surgical mode of treatment. ${ }^{12}$

Landau et al retrospectively reviewed the various treatment modalities for the management of the blunt liver injury in children. They analyzed the data of 311 paediatric patients with the history and chief complaint of blunt liver injuries and gathered information about the complete clinical and demographic details of these patients. They observed that the age of these paediatric patients ranged from 3 weeks to 12 years with mean age being 7 years. They also observed that road accident was the most common cause of thee injuries. From the results, they concluded that for the treatment of blunt liver trauma cases, non-surgical treatment is a successful method of treatment. ${ }^{13}$ Haan et al examined the successfulness of non-surgical management of patients having blunt splenic injuries. They retrospectively analyzed the splenic injured patients admitted to the general hospital and observed that over 600 patients were admitted with injuries to the spleen as a result of abdominal trauma. From the results, they concluded that splenic salvage for the treatment of splenic injuries can be successfully replaced by splenic embolization method of treatment. ${ }^{14}$

\section{CONCLUSION}

From the above results, the authors concluded that higher success rate of non-surgical treatment exists in patients having blunt hepatic trauma with hemodynamic stability. Future studies are recommended.

\section{REFERENCES}

1. Croce MA, Fabian TC, Menke PG, Waddle-Smith L, Minard G, Kudsk KA, et al. Nonoperative management of blunt hepatic trauma is the treatment of choice for hemodynamically stable patients. Results of a prospective trial. Ann Surg 1995; 221: 744753.

2. David Richardson J, Franklin GA, Lukan JK, Carrillo EH, Spain DA, Miller FB, et al. Evolution in the management of hepatic trauma: a 25-year perspective. Ann Surg 2000; 232:324-330.

3. Hurtuk M, Reed RL 2nd, Esposito TJ, Davis KA, Luchette FA. Trauma surgeons practice what they preach: The NTDB story on solid organ injury management. J Trauma 2006;61:243-254.

4. Trunkey DD. Hepatic trauma: contemporary management. Surg Clin North Am 2004; 84: 437-450.

5. Champion HR, Sacco WJ, Copes WS, Gann DS, Gennarelli TA, Flanagan ME. A revision of the Trauma Score. J Trauma. 1989; 29(5): 623-9. 
6. Baker SP, O'Neill B, Haddon W Jr, Long WB. The injury severity score: a method for describing patients with multiple injuries and evaluating emergency care. J Trauma. 1974; 14 (3): 187-96.

7. Civil ID, Schwab CW. The Abbreviated Injury Scale, 1985 revision: a condensed chart for clinical use. J Trauma. 1988; 28 (1): 87-90.

8. Peitzman $A B$, Richardson JD. Surgical treatment of injuries to the solid abdominal organs: a 50-year perspective from the Journal of Trauma. J Trauma 2010; 69:1011.

9. Jurkovich GJ. Selective non-operative management in 25737 patients with penetrating abdominal injuries $(\mathrm{Br} J$ Surg 2011; 99(Suppl 1): 157-167). Br J Surg 2012; 99 Suppl 1:164.

10. Petrowsky $H$, Raeder $S$, Zuercher L, et al. A quarter century experience in liver trauma: a plea for early computed tomography and conservative management for all hemodynamically stable patients. World J Surg 2012; 36:247.

11. Bismar HA, Alam MK, Al-Keely MH, Al Salamah SM, Mohammed AA. Outcome of nonoperative management of blunt liver trauma. Saudi Med J. 2004 Mar; 25(3): 294-8.

12. Ghnnam WM, Almasry HN, Ghanem MA. Non-operative management of blunt liver trauma in a level II trauma hospital in Saudi Arabia. Int J Crit IIIn Inj Sci. 2013 Apr; 3(2):118-23.
13. Landau A, van As AB, Numanoglu A, Millar AJ, Rode H. Liver injuries in children: the role of selective non-operative management. Injury. 2006 Jan; 37(1):66-71.

14. Haan JM, Bochicchio GV, Kramer N, Scalea TM. Nonoperative management of blunt splenic injury: a 5 -year experience. J Trauma. 2005 Mar; 58(3):492-8.

\section{Source of Support: Nil.}

Conflict of Interest: None Declared.

Copyright: (c) the author(s) and publisher. IJMRP is an official publication of Ibn Sina Academy of Medieval Medicine \& Sciences, registered in 2001 under Indian Trusts Act, 1882.

This is an open access article distributed under the terms of the Creative Commons Attribution Non-commercial License, which permits unrestricted non-commercial use, distribution, and reproduction in any medium, provided the original work is properly cited.

Cite this article as: Mohd Khalid, Mohd Mubashir. Comparatively Evaluation of Surgical and Non-Surgical Treatment of Blunt Hepatic Trauma. Int J Med Res Prof. 2016; 2(5):152-55. 